\title{
Vilanterol trifenatate for the treatment of COPD
}

\section{Mario Malerba, Alessandro Radaeli, Paolo Montuschi \& Jaymin B Morjaria}

To cite this article: Mario Malerba, Alessandro Radaeli, Paolo Montuschi \& Jaymin B Morjaria (2016): Vilanterol trifenatate for the treatment of COPD, Expert Review of Respiratory Medicine, DOI: $10.1080 / 17476348.2016 .1184976$

To link to this article: http://dx.doi.org/10.1080/17476348.2016.1184976

Accepted author version posted online: 04 May 2016.

Submit your article to this journal

View related articles $\widetilde{ }$

View Crossmark data $\nearrow$ 
Publisher: Taylor \& Francis

Journal: Expert Review of Respiratory Medicine

DOI: $10.1080 / 17476348.2016 .1184976$

\section{Vilanterol trifenatate for the treatment of COPD}

Mario Malerba ${ }^{1}$, Alessandro Radaeli ${ }^{2}$, Paolo Montuschi ${ }^{3}$, Jaymin B Morjaria ${ }^{4}$

Affiliations

1 Department of Internal Medicine, University of Brescia and ASST Spedali Civili, Brescia, Italy

2 Department of Emergency ASST Spedali Civili, Brescia, Italy

3 Department of Pharmacology, Faculty of Medicine, University Hospital Agostino Gemelli, Catholic University of the Sacred Heart, Rome, Italy

4 Department of Respiratory Medicine, Royal Brompton \& Harefield NHS Trust, Harefield Hospital, Hill End Road, Harefield, Middlesex, United Kingdom

Address for correspondence and reprints

Mario Malerba

Department of Internal Medicine

University of Brescia and ASST Spedali Civili

Brescia, Italy

e-mail: mario.malerba@unibs.it

tel: +39030 3995250 


\begin{abstract}
Introduction: Currently the treatment of chronic obstructive pulmonary disease (COPD) has limited effectiveness and there is a need to develop new drugs. International guidelines recommend the use of long-acting bronchodilators ( $\beta 2$ agonists and anticholinergics/muscarinics), inhaled steroids and associations between these drugs in the maintenance treatment of moderate-to-severe COPD.

Area Covered: Vilanterol trifenate is a new once-daily highly selective $\beta 2$-agonist available in USA and Europe in association with umeclidinium bromide (a long-acting anti-muscarnic agent) and fluticasone furoate (an inhaled corticosteroid) for the once-daily maintenance treatment of COPD. Vilanterol combined in fixed-dose treatments has been tested in numerous clinical trials involving thousands of patients.

Expert Commentary: These new once-daily formulations have the potential to improve compliance to long-term inhaled therapy. This paper will review the clinical and experimental data regarding vilanterol use in the regular treatment of COPD as well as provide a critical discussion of possible future treatment settings.
\end{abstract}

Key words: Vilanterol trifenate, umeclidinium bromide, fluticasone furoate, LABA, LAMA, COPD treatment. 


\section{INTRODUCTION}

Chronic obstructive pulmonary disease (COPD) is a chronic lung disease characterized by the presence of airflow limitation and bronchial inflammation [1]. It is considered one of the diseases with greatest impact on public health and the WHO estimates that COPD will become the third leading cause of death by 2030 worldwide [2].

The main objectives of COPD treatment are the prevention of decline in respiratory function, improvement of symptoms, prevention of exacerbations and avoidance of pulmonary and extrapulmonary complications. Treatment options depend on the stage of disease severity and the risk of exacerbation. However, the basis of therapy consists of bronchodilators and anti-inflammatory drugs administered topically [3].

The 2 main classes of long-acting bronchodilators act through different mechanisms of action: long-acting beta-2 ( $\beta 2$ )-adrenoceptor agonists (LABA) and muscarinic receptor antagonists (LAMA). Both classes of bronchodilators are associated with improvements in symptoms, rate and severity of exacerbations and exercise tolerance [4].

The Global Obstructive Lung Disease (GOLD) International guidelines recommend classification of patients with COPD into 4 categories $(A, B, C$ and $D)$ in relation to airflow limitation, severity of symptoms and the risk of exacerbation (patients with more severe symptoms or at higher risk are classified as groups Cor D) [1]. GOLD recommends the use of bronchodilators, LAMA or LABA, as maintenance therapy in patients with less severe symptoms; and in patients with increased symptoms combinations of fixed doses of LABA with LAMA or LABA with inhaled corticosteroids (ICS) [1]. In patients with moderate-to-severe COPD there is evidence that the combination of different classes of bronchodilators is more effective compared to using a single drug class [5]. 
In clinical practice, however, the prescription rate of combination drugs is very high. There is indeed the observation that adherence to treatment and compliance can be increased with combination treatments with once-daily administration [6].

Vilanterol trifenate (VIL) is a new LABA with 24 hours activity, for once-daily inhalation treatment use in association with LAMA or ICS for the treatment of COPD [7]. This paper reviews the use of VIL alone and in combination with ICS and LAMA in the treatment of COPD, and in combination with ICS for asthma. The paper will focus on VIL's pharmacokinetics and pharmcodynamics: efficacy, especially on lung function, and patient-reported outcomes such as exercise tolerance, improvement in symptoms and quality of life; and safety. Possible future treatment settings involving VIL in the treatment of COPD will also be critically discussed.

\section{VILANTEROL TRIFENATE (VIL)}

\subsection{Mechanism of Action and Structural Characteristics}

32-adrenoceptor agonists increase airflow into the lungs via relaxation of the airways. This is achieved by the relaxing of smooth-muscle in bronchial airways through the $\beta 2$-adrenoceptor Gprotein coupled receptor. Activation of the $\beta 2$-adrenoceptor stimulates G-protein as which in turn activates adenylyl cyclase to increase intracellular levels of $3^{\prime}-5^{\prime}$-cyclic adenosine monophosphate (CAMP). The enhanced levels of CAMP activate protein kinase A results in smooth-muscle relaxation either via an attenuation in myosin-regulatory light chain kinase activity or phosphorylation of Ca2+-dependent $\mathrm{K}+$ channels [7]. Stimulation of the latter with $\beta 2$ adrenoceptor agonists has also shown to be protein kinase $A$ independent [8].

There has been continuous development of $\beta 2$-adrenoceptor agonists from the late 1960 s in the form of salbutamol which is short acting [9), and in the 1990s in the form of salmeterol [10] and formoterol [11] as longer acting (for at least 12 hours) bronchodilation. In order to overcome the 
challenges of airways disease such as poor patient compliance either due to the frequency of dosing regimens and/or complexities of delivery, a new generation of longer acting bronchodilators (lasting 24 hours) have been developed [7, 12].

VIL is an antedrug analogue of salmeterol with a higher intrinsic activity at the 32 -adrenoceptor [13]. The development of VIL was based on the modification of the salmeterol molecule to create homochiral compounds with the (R)-configuration, as the (R)-enantiomer of salmeterol is more potent.

\subsection{Pharmacodynamics of VIL}

Preclinical studies of VIL using radio-ligand binding and CAMP studies in recombinant assays as well as human and guinea pig tissue systems have been used to characterize its $\beta 2$-adrenoceptor binding and functional properties.

Saturation binding studies report that VIL is bound either to one or two $\beta 2$-adrenoceptor affinity states. Irrespective of the receptor state VIL exhibits a high affinity interaction with the $\beta 2$ adrenoceptor. The affinity of VIL for the low affinity agonist state was comparable to salmeterol but significantly higher than that of formoterol and indacaterol [14].

In vitro assays of cells expressing human $\beta$-adrenoceptors, VIL was highly selective for the $\beta 2$ adrenoceptor, with over 1000 -fold selectivity over both $\beta 1$-adrenoceptors and $\beta 3$-adrenoceptors. VIL's $\beta 2$-adrenoceptor selectivity was similar to salmeterol however markedly higher than formoterol, indacaterol and isoprenaline [14]. The functional potency of VIL at the $\beta 2$ adrenoceptor was comparable to formoterol but markedly superior to salmeterol and indacaterol (8). Intrinsic efficacy at that $\beta 2$-adrenoceptor of indacaterol and VIL were similar, however significantly greater than salmeterol and less than formoterol [14]. In fact the intrinsic activity of 
VIL was lower than that of isoprenaline, the reference full $\beta 2$-adrenoceptor agonist, indicating that VIL, akin to salmeterol, is a partial $\beta 2$-adrenoceptor agonist.

In ex vivo human small airway assays, pre-contracted with histamine or carbachol, both VIL and salmeterol caused a concentration-related bronchodilation, exhibited a comparable half maximal effective concentration (EC50) and a similar efficacy (as measured by maximal percentage bronchodilation) with each spasmogen assessed [14].

In isolated guinea pig trachea, the mean onset of action for VIL was 5.8 minutes which was marginally higher than that for formoterol and indacaterol (4 minutes for both) but significantly more rapid than salmeterol with a time of onset of 15.2 minutes [14]. Human precision cut lung slices confirmed the significantly faster onset of VIL compared to salmeterol $\left(t_{1 / 2} 3.1\right.$ minutes versus 8.3 minutes respectively) [14].

Persistence and reassertion of $\beta 2$-adrenoceptor agonists using in vitro and ex vivo systems demonstrated that VIL, salmeterol and indacaterol were not readily washed out of the $\beta 2$ adrenoceptor and exhibited a longer persistence of action than for formoterol [14]. Importantly both VIL and salmeterol showed a significant duration of action compared to control at four hours, however only the former were shown to be significantly different from control-treated airways at 22 hours. Neither active agents demonstrated a significant level of bronchodilation at 28 hours [14].

\subsection{Pharmacokinetics of VIL}

In healthy humans' single oral administrations of up to $500 \mu \mathrm{g}$ of VIL was safe and well tolerated [14]. With a single oral dose of $200 \mu \mathrm{g}$ of VIL, at least $50 \%$ was orally absorbed. The primary route of elimination was via O-dealkylation to metabolites with negligible pharmacological activity, which were excreted predominantly in urine [15]. VIL represented $<0.5 \%$ of total drug-related 
material in plasma, demonstrating its extensive first-pass metabolism [15]. Hence, at the therapeutic inhaled dose level of $25 \mu \mathrm{g}$, VIL is unlikely to produce marked amount of pharmacologically active metabolites that may result in any unexpected toxicity.

Ketoconozole is a potent cytochrome P450 3A4 inhibitor. To assess the effects of ketoconazole versus placebo on single doses of VIL (study 1 ) or in combination with fluticasone furoate (FF)(FF/VI) (study 2) in healthy individuals, Kempsford et al conducted 2 randomized, doubleblind, two-way crossover studies [16]. As monotherapy VIL administration did not result in marked systemic pharmacodynamic alterations, however when combined with FF had less than a 2-fold increase in systemic exposure to FF and VIL; which may manifest the potential for AEs. Verapamil, a P-glycoprotein and moderate cytochrome P450 3A4 inhibitor has also been assessed in healthy subjects [17]. Following repeated doses of umeclidinium (a LAMA) (UMEC) monotherapy or in combination with VIL (UMEC/VIL) and verapamil on days 9-13, there was no increased systemic exposure to VIL and only a modest increase UMEC; hence unlikely to result in any meaningful drug-drug interactions. Hepatic and renal impairment can alter pharmacokinetic and pharmacodynamic properties of drugs. In patients with severe renal impairment FF/VI had no clinically important effects or tolerability on FF/VI when individually assessed [18]. Similarly, hepatic impairment has been shown to have no effects on systemic VIL exposure however in moderate and severe hepatic impairment, FF is associated with an increased systemic exposure and thus attenuated serum cortisol levels. Independently, VIL does not require any caution in patients with renal and hepatic impairment though in combination with FF may result in undesirable systemic corticosteroid effects due to FF.

In separate studies conducted by the same group on the pharmacodynamics in Japanese healthy

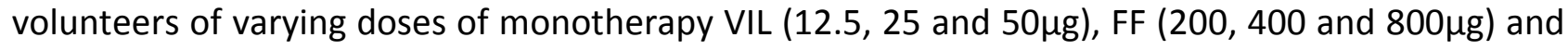
in combination (FF/VIL) $(800 / 50 \mu g)$ it was reported that there were no safety concerns or 
treatment-related AEs with repeated dosing of FF and VIL and single doses of FF, VIL and FF/VIL [19]. Systemic exposure to FF and VIL increased in a dose-dependent fashion, with marked serum cortisol reductions after 7-day administration at the highest FF dose of $800 \mu \mathrm{g}$. Although the heart rate increased with the higher VIL dose of $50 \mu \mathrm{g}$, this was not clinically significant. When combined with FF in patients with moderate-to-severe COPD, VIL (FF/VI) compared to placebo (FF/placebo) was not associated any marked differences in weighted mean (wm) heart rate, blood glucose and potassium, vital signs or ECG/Holter changes at 28 days [20]. There were however more treatment-related adverse events (AEs) in the FF/VI group especially oral candidiasis and dysphonia.

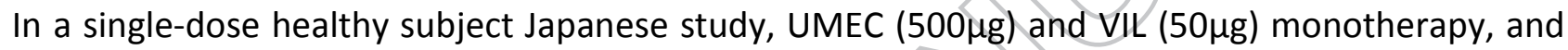
in combination (UMEC/VIL) were reported to have no marked systemic exposures or tolerability issues [21].More recently an open-labeled, randomized, crossover study to assess the pharmacokinetics, safety and tolerability of 2 inhaled UMEC/VIL combinations $(62.5 / 25$ and $125 / 25-\mu \mathrm{g}$ ) compared to their monocomponents (UMEC - 62.5 and $125 \mu \mathrm{g}$; VIL - 25 $\mu \mathrm{g}$ ) in 20 healthy Chinese subjects has been conducted [22]. Following repeat VIL dosing, time to maximum plasma concentration (tmax) was five minutes; with its accumulation at $25-66 \%$ of maximum plasma concentration (Cmax) and 17 to $43 \%$ based on AUC (0-2). No severe adverse events were reported with VIL use. Moreover no clinically important changes in vital signs, heart rate, or ECG parameters were observed irrespective of whether VIL was delivered as combination therapy or monotherapy. In a 28-day safety and tolerability double-blind, parallel group study in moderateto-severe COPD patients UMEC/VIL was compared to placebo by Feldman et al [23]. At the end of the study (day-28), there were no differences in wm heart rates over 0-6hrs, blood pressure measurements, minimum and maximum heart rates, ECG parameters, AEs and SAEs between the 
2 groups. UMEC and VIL were rapidly absorbed (mean $t$ (max) of 6 mins) with no suggestion of accumulation over the study period.

\subsection{Clinical Efficacy of VIL Monotherapy in COPD}

Hanania et al conducted a phase IIb, multicentre, randomized, placebo-controlled, parallel-group 28-day dose-ranging $(3,6.25,12.5,25$ or $50 \mu \mathrm{g})$ study of VIL in 602 COPD patients [24]. This study assessed the dose response, efficacy, and safety of VIL. The primary endpoint was change from baseline in trough forced expiratory flow in one second $\left(\mathrm{FEV}_{1}\right)$ at the end of the 28-day treatment period. It was reported that once-daily treatment with VIL at doses ranging from 3 to $50 \mu \mathrm{g}$ for 28 days produced statistically significant, dose-dependent improvements in trough $\mathrm{FEV}_{1}$ compared to placebo. Adjusted mean treatment differences of $\geq 100 \mathrm{~mL}$ versus placebo in both trough and 0 - to

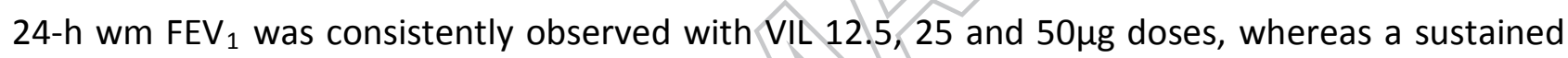
24-h duration of action was demonstrated at all doses of VIL throughout the 28-day treatment period. Bayesian analysis of trough $\mathrm{FEV}_{1}$ demonstrated that the 25 and $50 \mu \mathrm{g}$ groups had a higher probability (92\% and $99 \%$, respectively) that the true difference versus placebo would be $>100 \mathrm{~mL}$ compared with the other VIL dosed groups. Importantly, all doses of VIL administered were associated with a low incidence of AEs/SAEs, with no suggestion of effects on blood pressure, heart rate, ECG parameters, or blood glucose and potassium levels.

In another study, single doses of inhaled VIL $(25-100 \mu \mathrm{g})$ were administered to patients with mildto-moderate asthma and moderate-to-severe COPD, and 14 days repeated dosing to healthy controls to determine the safety, tolerability pharmacodynamics and pharmacokinetics of VIL [25]. All doses of VIL were well tolerated and the incidence and severity of adverse events were comparable to placebo. VIL administration resulted in no clinically significant abnormalities in vital signs, ECG parameters, and blood glucose or potassium levels. As expected all doses of VIL 
demonstrated increases in $\mathrm{FEV}_{1}$ from as early as five minutes of dosing, which were maintained up to 24 hours post-dose in subjects with asthma and COPD. In all subjects VIL was rapidly absorbed (healthy subjects Tmax 5 minutes; asthma and COPD subjects Tmax 10 minutes) with systemic exposure increasing in a dose-proportional manner. Marginal accumulation was noted on repeated dosing.

Unlike other bronchodilators, VIL is not available as a single agent and is approved for use in COPD only in a fixed-dose combinations with UMEC or FF. UMEC/VIL is orally inhaled via the dry powder inhaler (DPI) Ellipta ${ }^{\mathrm{TM}}$ which is easy to use and ensures the effective administration of a constant dose even across a range of inspiratory flows [26]. The dosage is one inhalation of UMEC/VIL $62.5 / 25 \mu \mathrm{g}$ once-daily equivalent to a delivered dose of $55 / 22 \mu \mathrm{g}$. UMEC/VIL is approved for inhalation for the long term regular treatment of COPD in several countries including the US and EU $[27,28]$.

In the EU, FF/VIL is indicated for symptomatic adult patients with COPD with a predicted postbronchodilator $\mathrm{FEV}_{1}<70 \%$ and an exacerbation history despite regular bronchodilator therapy [29]; and in the US for the maintenance treatment of airflow obstruction and for reducing exacerbations [30] The recommended dosage of FF/VIL is $100 / 25 \mu$ g once-daily, with higher dosages associated with low tolerability and enhanced risk of pneumonia [31]. FF/VIL is also delivered by inhalation by the DPI ELLIPTA ${ }^{\mathrm{TM}}$.

\section{UMECLIDINUM AND VILANTEROL IN COMBINATION IN THE TREATMENT OF COPD UMECLIDINUM BROMIDE}

\subsection{PHARMACOLOGY OF UMEC}


UMEC is a novel LAMA, similar to tiotropium bromide (TIO), with a strong affinity to specific receptors namely M3. UMEC is quickly absorbed (Tmax, 5-15 minutes) with slow functional reversibility. These characteristics allow a faster onset and prolonged duration of action [32]. After single or repeated dosing only $1 \%-2 \%$ of the total dose is excreted unchanged in the urine, and an accumulation after repeat dosing between 1.5-1.9-fold [33] In patients with COPD single and repeat doses of UMEC produced clinically relevant 24-hour lung function improvements and were well tolerated [33] . In moderate-to-severe COPD patients the efficacy of once-daily UMEC using 125,250 , and $500 \mu \mathrm{g}$ showed significantly improved $\mathrm{FEV}_{1}$ versus placebo [34]. In a 12-week study in COPD subjects, administration of UMEC $62.5 \mu \mathrm{g}$ and $125 \mu \mathrm{g}$ improved lung function as well as breathlessness symptoms and enhanced health status [35].

As previously mentioned, LABAs act via 32 -adrenoceptors, while LAMAs through antimuscarinic/cholinergic receptors. The differing modes of actions of UMEC, a LAMA, and VIL, a LABA, in the treatment of COPD may be important, as their action via different receptors may potentially permit synergistic therapeutic benefits which may be superior to the monotherapies. This may be particularly pivotal in patients not sufficiently controlled with monotherapy bronchodilators [36].

\subsection{CLINICAL TRIALS ASSESSING SAFETY AND EFFICACY OF UMEC/VIL}

Several recent trials [23, 37-45] (collectively enrolling more than 9.000 patients with COPD) assessed the efficacy and safety of treatment with UMEC/VIL at different doses compared with placebo, the monocomponents (UMEC and VIL), and bronchodilators or anti-inflammatory treatments. The trials enrolled patients with stable COPD, mostly moderate-to-severe stage with mediam age 60 years andboth sexes satisfactorily represented (males about 68\%). Notably, approximately half of the patients were active smokers and were permitted to take concomitant 
ICS therapy. The duration of the studies ranged from 12 to 52 weeks (Table 1 compares the main data of the cited studies concerning UMEC/VIL; Figures 1 and 2 report results on trough $\mathrm{FEV}_{1}$ at the end of the study of the mentioned papers).

\subsubsection{CLINICAL EFFICACY OF UMEC/VIL COMBINATION THERAPY VERSUS PLACEBO IN THE REGULAR}

\section{TREATMENT OF STABLE COPD}

Two 12-week double-blind randomized 12-week, crossover clinical studies specifically addressed the effects of the treatment with UMEC/VIL in COPD patients on exercise tolerance compared to placebo. [41]Endurance improvements were observed with UMEC/VIL doses $(125 / 25 \mu \mathrm{g}$ or

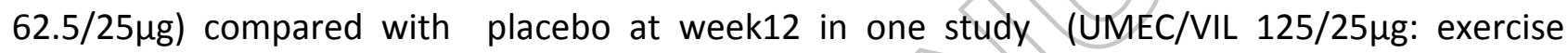
endurance time (EET) difference from placebo $65.8 s ; p=0.005 ;$ UMEC/VIL 62.5/25 $\mu \mathrm{g}$ : 69.4s; $p=$ 0.003), but not in the second study where a strong placebo effect was observed making the difference with the treated group insignificant. Both studies showed trough $\mathrm{FEV}_{1}$ improvements at week-12 for both UMEC/VIL doses.

Cardiovascular safety was specifically addressed in a 28-day randomized placebo-controlled study

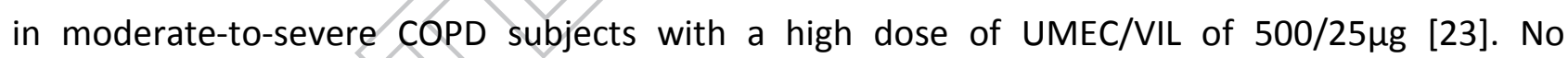
significant changes in pulse rate, blood pressure, or QTc relative to placebo were observed.

Generally, compared to placebo UMEC/VIL produced significant improvement in numerous outcomes of clinical efficacy (lung function and quality of life) in COPD patients. In a 24-week double-blind, placebo-controlled, parallel-group study by Donohue et al [39] comparing placebo to

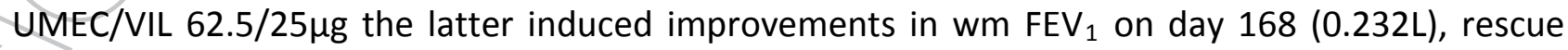
salbutamol use, dyspnoea index and health-related quality scales (The Shortness of Breath with Daily Activities and St. George's Respiratory Questionnaire (SGRQ)). UMEC/VIL reduced 
significantly the risk of COPD exacerbations relative to placebo, showing also a safety profile comparable with placebo.

In particular the tolerability profile of UMEC/VIL tested in clinical trials [38-40,42] did not showed significant difference from placebo. The most commonly reported adverse events were headache and nasopharyngitis. The rate of typical effects due to anti-cholinergic and $\beta 2$-receptor agonists associated with the use of LABAs and LAMAs was found in $<3 \%$ of the cited trials.

\subsubsection{CLINICAL EFFICACY OF UMECLIDINIUM/VILANTEROL IN THE REGULAR TREATMENT OF} STABLE COPD: COMPARISON WITH OTHER TREATMENTS

Phase II and III trials of UMEC/VIL in patients with COPD were mainly comparisons of treatment at doses of $125 / 25 \mu \mathrm{g}$ or $62.5 / 25 \mu \mathrm{g}$ ) compared with the mono-components: VIL $25 \mu \mathrm{g}[37-41,45]$; UMEC $125 \mu \mathrm{g}$ or $62.5 \mu \mathrm{g}[31-41,45]$; TIO $18 \mu \mathrm{g} ;[38,42]$ or with fluticasone propionate/salmeterol (FP/SAL) $250 / 50 \mu \mathrm{g}$ or $500 / 50 \mu \mathrm{g}[43,44]$.

\subsubsection{UMEC/VIL vs UMEC}

UMEC was assessed at two different doses of $62.5 \mu \mathrm{g}$ and $125 \mu \mathrm{g}$, with the studies reporting a significant improvement in pulmonary function $(p<0.0001)$ expressed as mean change from baseline in trough FEV 1 and significantly increased percentage of patients achieving a rise of $100 \mathrm{~mL}$ above baseline in trough $\mathrm{FEV}_{1}$ in favour of patients taking UMEC/VIL compared to those patients treated with UMEC alone [37-39].

No significant difference in SAEs or mortality during treatment was noted comparing the treatment regimens. Subjectively, UMEC/VIL increased significantly the percentage of patients with a minimal clinically important difference (MCID) in TDI and use of rescue medications compared with UMEC monotherapy [43]. From a COPD exacebtion perspective UMEC/VIL 
significantly reduced the number of patients with at least one exacerbation [44]. Also, treatment with UMEC/VIL was associated with a lower number of study withdrawals compared to UMEC

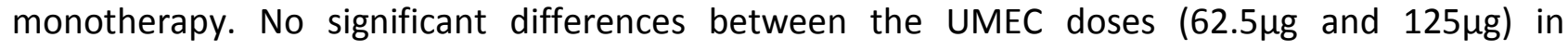
combination with VIL, or monotherapy was observed.

\subsubsection{UMEC/VIL vs VIL}

Three randomized controlled trials evaluated the comparison between UMEC/VIL and VIL alone using different UMEC doses $(62.5 \mu \mathrm{g}$ and $125 \mu \mathrm{g})$ for the efficacy and safety in [37-39]. Overall, the trials showed that the mean change from baseline in trough $\mathrm{FEV}_{1}$ increased significantly compared to VIL alone. Similar improvements in favour of UMEC/VIL in peak FEV $_{1}$ compared to VIL monotherapy were also reported [38].

Treatment differences between UMEC/VIL and VIL alone were not as distinctly defined for healthrelated quality outcomes measures as they were for lung function assessments [37], however UMEC/VIL showed an increased odds of achieving a TDI response than VIL monotherapy in two of the considered studies [37,38]. Only one of the cited studies [37] found a reduction in the use of albuterol in favour of UMEC/VIL treated COPD patients compared to those treated with VIL only. There were no reported differences between UMEC/VIL and VIL monotherapy in change in healthrelated quality scales or time to first exacerbation.

In order to clarify the differential efficacy of UMEC and VIL monotherapies compared to combined treatment, two randomized, double-blind studies enrolling 207 and 182 moderate-to-severe COPD patients were conducted [45]. All the patients were randomized to one of 6 treatment sequences

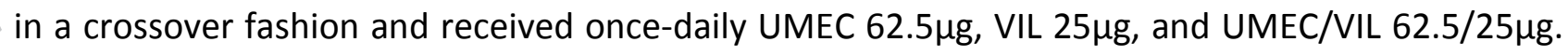
Using this methodology the authors could identify UMEC/VIL-induced improvements in outcome measures in patients defined as UMEC or VIL responders compared with non-responders. Non- 
responders to both UMEC and VIL monotherapy achieved a significant lung function response when UMEC/VIL was administered. In these patients, response to UMEC/VIL was more than the additive effect of the monotherapies

\subsubsection{UMEC/VIL vs tiotropium}

The comparison between UMEC/VIL and TIO have been assessed in three studies $[38,42]$. The data report a significant improvement in change from baseline in trough $\mathrm{FEV}_{1}$ though this was $<100 \mathrm{ml}$ $(p<0,001)$. The use of UMEC/VIL showed an enhancement of $0-6 \mathrm{~h}$ Wm FEV 1 and peak FEV 1 compared with TIO. Moreover UMEC/VIL significantly improved the odds of achieving an increase in $\mathrm{FEV}_{1}$ of $\geq 12 \%$ or $200 \mathrm{ml}$ above baseline in the $0-6 \mathrm{~h}$ post-dose on day- 1 and that of achieving an $\mathrm{FEV}_{1}>100 \mathrm{ml}$ above baseline at the end of treatment compared to TIO. UMEC/VIL administration significantly reduced the use of rescue albuterol compared to TIO in all the cited studies, and the SGRQ in one study [42]. No differences were observed for all the others variables including the rate of AEs, SAEs, withdrawals, deaths or COPD exacerbations.

The economic impact in the use of any therapy is important and a cost-benefit analysis undertaking is pivotal. Recently, both Punekar et al and Miravittles et al $[46,47]$ assessed the costeffectiveness of UMEC/NIL versus TIO monotherapy using a treatment-specific COPD economic model. The analyses suggested that UMEC/VIL can be considered a more cost-effective alternative to TIO in COPD.

\subsubsection{UMEC/VIL vs salmeterol/fluticasone propionate (SAL/FP)}

Three 12-week trials enrolling more than 2,000 patients with COPD compared UMEC/VIL

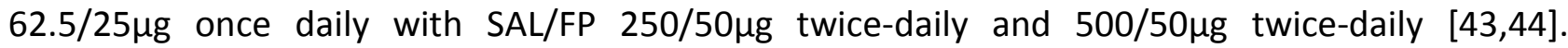
UMEC/VIL was associated with a significantly improved pulmonary function (mean change from 
baseline in trough $\mathrm{FEV}_{1}$ ) in all three trials. One study reported a reduction in rescue medication use in favour of patients treated with UMEC/VIL [44]. No differences were found in the remaining variables considered.

\section{FLUTICASONE FUROATE AND VILANTEROL IN COMBINATION IN THE TREATMENT OF COPD}

\subsection{PHARMACOLOGY OF FLUTICASONE FUROATE (FF)}

Like other ICS, FF acts primarily on a cellular level promoting the inhibition of the proinflammatory action of nuclear factor kB (NF-kB), reducing transcription of pro-inflammatory genes. The topical action occurs principally via alveolar macrophages, epithelial and endothelial cells culminating in an attenuation of bronchial hyperresponsiveness, airway oedema and inflammatory infiltration of lower airways $[48,49]$. FF is a new tri-fluorinated glucocorticoid with an enhanced glucocorticoid receptor affinity $(G R)$; it is rapidly associated and slowly dissociated from the GR compared to dexamethasone, budesonide or mometasone [50]. FF and FP are more potent than budesonide or mometasone in the reduction of pro-inflammatory cytokine production in lung tissue [51] and the former has a prolonged duration of action allowing a once-daily dosing [52].

The different actions of ICS and LABA in the treatment of COPD, targeting different receptors suggests potential synergistic interactions, leading to enhanced clinical effects than those achieved with single agent therapy [53].

\subsection{CLINICAL TRIALS ASSESSING SAFETY AND EFFICACY OF FF/VIL}

Several recent studies enrolling more than 20000 patients have assessed the efficacy and safety treatment with FF/VIL at different doses compared with placebo [20,54]; monocomponents (FF and VIL) and placebo [55, 56, 57]; VIL monotherapy [57]; and other bronchodilators/anti- 
inflammatory treatments $[58,61]$. The studies enrolled adult patients with stable moderate-to-

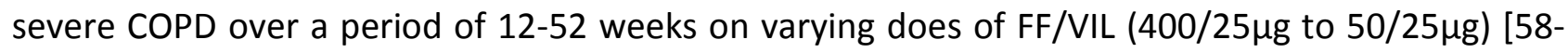
$60,58,59]$. Three studies required a dyspnoea score of $\geq 2$ (on a scale of $1-4$ ) on the modified Medical Research Council dyspnoea scale (mMRC) [54-56]. (Table 2 compares the main data of the cited studies concerning FF/VIL; Figure3 reports results on trough FEV $_{1}$ at the end of the study of the mentioned papers).

\subsubsection{FF/VIL Comparison with placebo only}

In a phase III crossover study in 54 patients with moderate-to-severe COPD [54], all three doses of FF/VIL $(200 \mu \mathrm{g}, 100 \mu \mathrm{g}$ and $50 \mu \mathrm{g}$ of FF, with VIL $25 \mu \mathrm{g})$ produced a significantly higher $0-24 \mathrm{~h}$ change from baseline in wm FEV 1 than placebo (period days 28-29): adjusted mean improvements from placebo in $\mathrm{FEV}_{1}$ for FF/VIL were $220-236 \mathrm{mLs}(\mathrm{p}<0.001)$. A previous 4-week trial [20] with higher FF dose $(400 \mu \mathrm{g})$ indicated that the FF/VIL-treated group had statistically greater improvements compared with placebo in trough $\mathrm{FEV}_{1}$ (mean difference $183 \mathrm{ml}$ ) and 0-4h post-dose $\mathrm{wm} \mathrm{FEV}_{1}$ (mean difference $236 \mathrm{ml}$ ). In both trials $\mathrm{FF} / \mathrm{VIL}$ was well tolerated however in the trials administering the higher FF dose, an increased prevalence of oral candidosis and dysphonia were reported.

\subsubsection{FF/VIL Compared with Individual Components and Placebo}

Two 24-week trials in patients with moderate-to-severe COPD assessed the efficacy of different

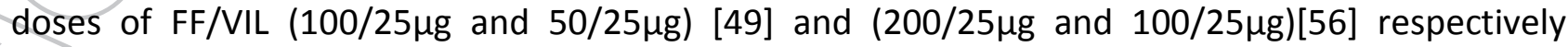
compared to its monocomponents and placebo. In the groups treated with FF/VIL the lung function (wm FEV 1 and trough $\mathrm{FEV}_{1}$ at day-168) [56], was improved compared with placebo and $\mathrm{FF}$ monotherapy although in one study the improvements were not statistically significance between 
FF/VIL and FF [56]. When compared with VIL alone, treatment with FF/VIL in both trials showed no significant difference for the co-primary endpoints assessed. No safety problems were signalled in the studies.

The Study to Understand Mortality and Morbidity in COPD (SUMMIT) prospectively evaluated the effect of FF/VI 100/25 $\mu \mathrm{g}$ and its monocomponents compared with placebo on survival in subjects with moderate COPD (predicted FEV $1 \geq 50$ and $\leq 70 \%$ ) and with a history of, or at increased risk for developing, cardiovascular disease [57]. The study enrolled more than 16.000 patients and consisted of a 4-10 day run-in period, variable treatment period until the required number of events was achieved, and a 1-week follow-up period. No significant difference was observed in terms of survival rate amongst the treatments and placebo. Mortality was $12.2 \%$ lower in the FF/VI-treated group compared to the placebo group, but was not statistically significant $(p=0.137)$. Similarly there was no marked difference in the risk for an on-treatment cardiovascular event (a secondary end point defined as cardiovascular death, myocardial infarction, stroke, unstable angina, or transient ischemic attack); $7.4 \%$ lower with FF/VI compared to placebo $(p=0.475)$. A lower decline in $\mathrm{FEV}_{1}$ was observed when comparing FF/VIL-treated patients with placebo or VIL alone, and with FF $100 \mu \mathrm{g}$ compared to VIL monotherapy.

Two alike studies conducted by Dransfield et al [58] addressed the exacerbation rate between once-daily FF/VIL and VIL monotherapy in patients with moderate-to-severe COPD. In one of the studies, no significant difference in exacerbation rate was noted between the 200/25 $\mu \mathrm{g}$ FF/VILtreated group and the VIL-treated group (mean events/yr 0.90 vs 1.05 ; ratio 0.9 ). Due to the statistical hierarchy used in the study no significance could be inferred for the FF/VIL 50/25 $\mu$ g and $100 / 25 \mu$ g groups, albeit that there were some differences between the 2 treatments in favour of FF/VIL. In the second study, significantly less exacerbations (moderate and severe) were observed in all FF/VIL-treated groups than in the VIL-treated group ( $p=0.0398$ for the $50 / 25 \mu$ g group, 
$p=0.0244$ for the $100 / 25 \mu$ g group, and $p=0.0004$ for the $200 \mu g$ group). The pooled analysis reported significantly fewer exacerbations in all FF/VIL groups than in VIL monotherapy. Moreover diary dyspnoea scores, rescue medication use and night-time awakenings showed improvements

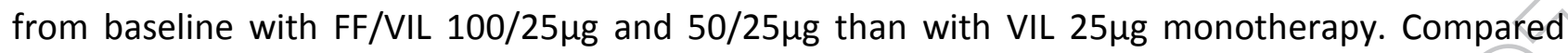

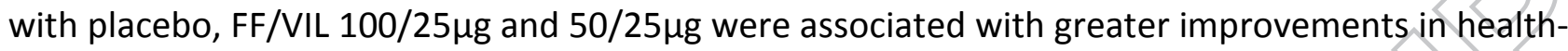
related quality questionnaires $[55,56]$.

\subsubsection{FF/VIL Compared with Fluticasone Propionate/Salmeterol (FP/SAL)}

Three 12 week studies comparing FF/VIL and FP/SAL have been conducted by Dransfield et al [59] enrolling overall 1858 patients with moderate to very severe COPD comparing FF/VIL 100/25 $\mu$ g once-daily with FP/SAL 250/50 $\mathrm{gg}$ twice-daily. The results of the trials were conflicting: In Study 1, the treatment difference of $0-24 \mathrm{~h}_{\text {w }} \mathrm{FEV}_{1}$ between FF/VIL and FP/SAL was statistically significant (80mL; $p<0.001)$ while in Studies 2 and 3, the differences $(29 \mathrm{~mL}$ and $25 \mathrm{~mL}$ respectively) were not. When the analysis was pooled an increase of $41 \mathrm{ml}$ which was statistically significant $(p<0.001)$ was observed. Time to onset differences between groups was statistically significant in Study 1 $(p<0.012)$ and the pooled data $(p<0.018)$. The other outcomes did not showed any difference between groups (change from baseline trough $\mathrm{FEV}_{1}$ after 12 weeks; change from baseline in FVC on day-84, the proportion of patients demonstrating a $100 \mathrm{~mL}$ increase in $\mathrm{FEV}_{1}$, and, in Studies 1 and 2 only, pre-dose inspiratory capacity (IC) at day- 84 and rescue medication use. The frequency of AEs was similar between the treatment arms (FF/VI 27\%; FP/SAL 28\%). Headache and nasopharyngitis were the most frequent events, occurring in about $5 \%$ of patients in either treatment group.

In another 12-week study [60] assessing the efficacy of FF/VIL 100/25 $\mu$ g once-daily with FP/SAL 500/50 $\mu$ g twice-daily in 528 mild-to-severe COPD patients showed no significant difference 
between the two study arms $(22 \mathrm{~mL} ; \mathrm{p}=0.282)$. However, a post-hoc comparison of changes in wm $\mathrm{FEV}_{1}$ between treatment arms showed differences from $0-4 \mathrm{~h}$ and $0-12 \mathrm{~h}$ post-dose. FF/VIL demonstrated a mean improvement of 4.3 units compared to 3 units with FP/SAL in SGRQ scores; suggesting a modest, but statistically insignificant positive effect of FF/VIL on patient's health status.

\subsubsection{FF/VIL Compared with TIO}

Recently. A study using once-daily FF/VIL $100 / 25 \mu \mathrm{g}$ with TIO $18 \mu \mathrm{g}$ for 12 weeks in 623 subjects COPD moderate-to-severe (baseline $\mathrm{FEV}_{1} 47 \%$ and $50 \%$ predicted in FF/VIL and TIO groups respectively) with cardiovascular co-morbidities or at least one current cardiovascular risk factor (hypertension, hypercholesterolemia, or treated diabetes mellitus) has been conducted [61]. Changes from baseline in $24 \mathrm{~h}$ wm FEV 1 and trough $\mathrm{FEV}_{1}$, were similar between the treatment groups (Figure 3). Subgroup analysis on subjects with bronchial reversibility reported a greater $24 \mathrm{~h}$ wm FEV 1 in the FF/VIL group (181mL) compared with the TIO group (110mL). Statistical hierarchy did not permit any other statistical inference for secondary endpoints. Increase in $\mathrm{FEV}_{1}>100 \mathrm{~mL}$ from baseline, trough $\mathrm{FEV}_{1}$ at day-84, changes from baseline symptoms, rescue medication use, health-related questionnaires were similar in both groups with the exception for the individual SGRQ-C components where FF/VIL consistently had a reduced component score more than TIO, and only the FF/VIL group achieved the MCID for symptoms across all time points. More FF/VILtreated than TIO-treated subjects experienced an AE (7 vs $4 \%$ respectively) although more TIOtreated than FF/VI-treated subjects were withdrawn from the study due to AEs (4\% vs $2 \%$ respectively). Fewer subjects in the FF/VIL group (2\%) experienced a COPD exacerbation than in the TIO group (4\%), and pneumonia was reported in three subjects during treatment with FF/VI. 


\subsubsection{Triple therapy}

Two 12-week, double-blind, parallel-group trials with a total of 1238 patients with moderate-tosevere COPD were conducted to assess the efficacy and safety of placebo, UMEC $62.5 \mu \mathrm{g}$ and $125 \mu \mathrm{g}$ added to $100 / 25 \mu \mathrm{gF} / \mathrm{VI}$ [62]. Although there were no safety issues, at day-85 subjects on triple therapy had statistically and clinically significant improvements in lung function compared with the group treated only with FF/VIL in patients with COPD (FF/VIL+UMEC $62.5 \mu \mathrm{g} 0.124 \mathrm{~L} ; \mathrm{FF} / \mathrm{VIL}+\mathrm{UMEC} 125 \mu \mathrm{g} 0.128 \mathrm{~L}$; above placebo and FF/VIL respectively; both $\mathrm{p}<0.001$ ). In both studies $0-6 \mathrm{~h}$ post-dose FEV1 at day-84 and a greater odds of having an increase of $\mathrm{FEV}_{1}$ of $>100 \mathrm{~mL}$ above baseline was clinically and statistically significant with the addition of UMEC. There were no differences in parameters of health status, COPD exacerbations and safety profiles between the two treatments. . In one of the studies the use of rescue medication was significantly reduced with UMEC addition. Overall, these findings imply clinical meaningful improvements of adding UMEC to FF/VIL in the treatment of stable COPD.

\section{COMPARISON STUDIES}

In the last year, interesting network meta-analyses (NMA) have investigated the relative clinical benefit of currently available LAMA/LABA and or ICS/LABA fixed-dose combinations. Huisman et al [63] compared UMEC/VI, indacaterol/glycopyrronium (QVA149), formoterol plus TIO, salmeterol plus TIO, or indacaterol plus TIO. They failed to find any significant difference in efficacy among the combination treatments on trough $\mathrm{FEV}_{1}$, TDI score or heath-related quality related questionnaires (SGRQ), suggesting that these fixed-dose combinations had comparable efficacy. Hence, suggesting that dual bronchodilators may provide better outcomes (lung function, quality of life, symptom scores and moderate-to-severe exacerbation rates) in comparison to monotherapies in COPD patients. Oba et al obtained similar conclusions [64]. 
In another meta-analysis [65] comparing LAMA/LABA (QVA149 and UMEC/VI) with LABA/ICS (salmeterol/FP) reported significantly favourable effects of LAMA/LABA on trough FEV 1 , TDI, less exacerbations and less pneumonia compared to ICS/LABA.

More recently, Schlueter et al [66] published a NMA comparing the efficacy of LAMA/LABA fixeddose formulations considering also the impact on treatment effects of COPD severity, concomitant ICS use at baseline and exacerbation history. No significant efficacy analyses were noted considering the concomitant use of ICS at baseline, the severity of COPD at baseline or the history of exacerbations, except for a favourable effect on trough $\mathrm{FEV}_{1}$ for TIO/olodaterol $5 / 5 \mu \mathrm{g}$, QVA149

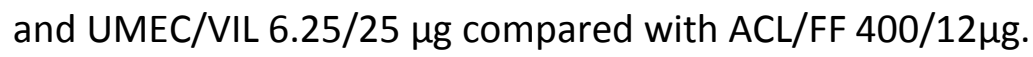

The results of these meta-analyses, although relevant are not definitive to determine which treatment combination may be superior and safer in the different clinical conditions. This may be best determined by direct comparison with head-to-head randomized controlled trials.

\section{EXPERT COMMENTARY}

The available experimental data shows that the VIL, although not available as a single agent, has a high receptor-binding profile for the $\beta 2$-receptors and improved functional potency compared to some of the other $\beta$-agonists.

Data emerging from clinical trials have shown that both in combination with FF and with UMEC [67], VIL once-daily in patients with moderate-to-severe COPD provided significant improvements in terms of lung function, but only in some cases provided benefits in COPD exacerbations rate and symptoms scores or life quality outcomes. The association LAMA and LABA (VI/UMEC) demonstrated significant improvements of lung function in moderate COPD compared with other treatments such as TIO and FP/SAL, while the association FF/VIL failed in the majority of the studies to provide a clear benefit if compared with other active treatments; less clear are the 
results for other outcomes in many large randomized trials. These data taken together would suggest that VIL use in patients with COPD would benefit those who require dual bronchodilation or protection from exacerbations. To date, it is not yet clear in which COPD therapeutic step to allocate the multiple associations with VIL such as triple therapy or ICS/LABA. An important factor to be considered is that VIL has the potential to improve poor compliance to the chronic treatment of patients with COPD by its ability to be administered once-daily. Additionally the Ellipta $^{\mathrm{TM}}$ delivery device enables drug delivery with minimal number of maneuvers necessary for activation, consequently reducing the risk of patient error and hopefully improving patient compliance in the real life. The device was developed to permit standardized distribution of the active compounds in the airways even in cases of poor inspiratory capacity; two characteristics particularly appreciated by patients.

\section{FIVE-YEAR VIEW}

The critical goal of COPD management is to decrease disease progression and mortality, and avoid exacerbations. Newly developed bronchodilators, such as VIL, have improved considerably the bronchodilatory effects as well as patient symptoms and quality of life; however current therapies including LABA and LAMA fail to substantially attenuate the critical goals of COPD management. As reported in the SUMMIT study [57] FF/VIL combination provides no mortality benefit in patients with moderate COPD and history of or risk for cardiovascular disease. Although the primary end point was not met, the study indicates a beneficial effect on lung function decline (a secondary outcome).

In the near future we expect to have some answers to still open questions about the impact of once-daily therapy on the efficacy tolerability and safety in clinical practice of the treatment of COPD. In particular, if once-daily treatment will enable greater clinical and functional stability to 
patients with COPD. Effects of VIL's associations on the future treatment of COPD patients are obviously unknown particularly considering that COPD is a chronic progressive condition, and patients with COPD commonly undergo treatment changes for type of medications or dose. New trials directly comparing new LAMAs, LABAs and ICS fixed-dose combinations will be essential to assess the true advantages, or lack of, of VIL-associated therapies over others.

\section{KEY ISSUES}

- Vilanterol is a new high selective once-daily acting $\beta 2$-agonist with a demonstrated significant bronchodilation action.

- Unlike other long-acting $\beta 2$-agonists, vilanterol is not available as a single agent and is approved for use in COPD only in a fixed combinations associated with umeclidinium (dosage $62.5 / 25 \mathrm{mcg}$ once-daily) or fluticasone furoate (dosage $100 / 25 \mathrm{mcg}$ once-daily).

- Vilanterol fixed-dose combinations with fluticasone furoate represents first once-daily combination of LABA/ICS for stable COPD .

- Vilanterol in association with umeclidinium and fluticasone furoate was well tolerated and demonstrates improvements in pulmonary function, exacerbation rates and health-related quality parameters compared to placebo in the treatment of moderate-to-severe COPD

- Once-daily vilanterol in combination with umeclidinium demonstrates improvements in pulmonary function directly compared with tiotropium $18 \mathrm{mcg}$ once-daily and fluticasone propionate with salmeterol $250 / 50 \mathrm{mcg}$ twice-daily in the treatment of moderate-severe COPD.

- In network meta-analyses vilanterol association treatments showed equal efficacy and safety compared with other fixed-dose combinations approved for treatment of stable COPD. 


\section{Declaration of Interests}

M Malerba has received sponsorship and educational grants from various pharmaceutical companies including Chiesi, Menarini, Mundipharma and Pfizer. JB Morjaria has received fees and sponsorship to attend or speak at the ERS, ATS and BTS conferences, for educational grants, and for being on the advisory boards of various pharmaceutical companies including Novartis, Boehringer Ingelheim, GlaxoSmithKline, Chiesi, MSD, Pfizer, Almirall, Teva, Napp and Astra Zeneca. The authors have no other relevant affiliations or financial involvement with any organization or entity with a financial interest in or financial conflict with the subject matter or materials discussed in the manuscript apart from those disclosed.

\section{REFERENCES}

Reference annotations

$*$ Of interest

** of considerable interest

**1. From the Global Strategy for the Diagnosis, Management and Prevention of COPD, Global Initiative for Chronic Obstructive Lung Disease (GOLD) 2016. Available from: http://www.goldcopd.org/. Accessed 20 February 2016

International Guidelines highlighting the most important points of COPD, contemporary paradigm for diagnosis and treatment

2. Gras J. Umeclidinium/vilanterol fixed-dose combination for COPD. Drugs Today. 2014;50(3):231-8.

* A comprehensive review of UMEC/VIL use in COPD treatment 
3.Donohue JF, Ohar JA. Bronchodilator therapy of airway disease. In: Chung KF, Barnes PJ, editors. Pharmacology and Therapeutics of Airway Disease. New York: Informa Healthcare USA; 2009:198225.

4. Ohar JA, Donohue JF. Mono- and combination therapy of long-acting bronchodilators and inhaled corticosteroids in advanced COPD. Semin Respir Crit Care Med. 2010;31(3):321-333.

5. Rodrigo GJ, Plaza V, Castro-Rodríguez JA. Comparison of three combined pharmacological approaches with tiotropium monotherapy in stable moderate to severe COPD: a systematic review. Pulm Pharmacol Ther. 2012 Feb;25(1):40-7.

6. Cazzola M, Matera MG. Novel long-acting bronchodilators for COPD and asthma. $\mathrm{Br} \mathrm{J}$ Pharmacol. 2008 Oct;155(3):291-9.

* 7. Malerba M, Radaeli A, Morjaria JB. Therapeutic potential for novel ultra long-acting beta2agonists in the management of COPD: biological and pharmacological aspects. Drug Discov Today. 2012 May;17(9-10):496-504.

* A comprehensive review of ultra LABA treatment in COPD

8. Johnson EN, Druey KM. Heterotrimeric G protein signaling: role in asthma and allergic inflammation. J Allergy Clin Immunol. 2002 Apr;109(4):592-602.

9. Cullum VA, Farmer JB, Jack D, et al. Salbutamol: a new, selective beta-adrenoceptive receptor stimulant. Br J Pharmacol. 1969 Jan;35(1):141-51.

10. Johnson M, Butchers PR, Coleman RA, et al. The pharmacology of salmeterol. Life Sci. $1993 ; 52(26): 2131-43$.

11. Anderson GP. Formoterol: Pharmacology, molecular basis of agonism, and mechanism of long duration of a highly potent and selective beta 2-adrenoceptor agonist bronchodilator. Life Sci. 1993;52(26):2145-60. 
12. Cazzola M, Calzetta L, Matera MG. Beta(2) -adrenoceptor agonists: current and future direction. Br J Pharmacol. 2011 May;163(1):4-17.

13. Procopiou PA, Barrett VJ, Bevan NJ, et al. Synthesis and structure-activity relationships of longacting beta2 adrenergic receptor agonists incorporating metabolic inactivation: an antedrug approach. J Med Chem. 2010 Jun 10;53(11):4522-30.

14. Slack RJ, Barrett VJ, Morrison VS, et al. In vitro pharmacological characterization of vilanterol, a novel long-acting beta2-adrenoceptor agonist with 24-hour duration of action. J Pharmacol Exp Ther. 2013 Jan;344(1):218-30.

15. Harrell AW, Siederer SK, Bal J, et al. Metabolism and disposition of vilanterol, a long-acting beta(2)-adrenoceptor agonist for inhalation use in humans. Drug Metab Dispos. 2013 Jan;41(1):89100.

16- Kempsford R, Allen A, Bal J, Rubin D, et al. The effect of ketoconazole on the pharmacokinetics and pharmacodynamics of inhaled fluticasone furoate and vilanterol trifenatate in healthy subjects. Br J Clin Pharmacol. 2013 Jun;75(6):1478-87

17 Mehta R, Kelleher D, Preece A, et al. Effect of verapamil on systemic exposure and safety of umeclidinium and vilanterol: a randomized and open-label study. Int J Chron Obstruct Pulmon Dis. 2013;8:159-67

18 Allen A, Davis A, Hardes K, et al. Influence of renal and hepatic impairment on the pharmacokinetic and pharmacodynamic properties and tolerability of fluticasone furoate and vilanterol in combination. Clin Ther. 2012 Dec;34(12):2316-32

19 Nakahara N, Wakamatsu A, Kempsford R, et al. The safety, pharmacokinetics and pharmacodynamics of a combination of fluticasone furoate and vilanterol in healthy Japanese subjects. Int J Clin Pharmacol Ther. 2013 Aug;51(8):660-71 
20 Lötvall J, Bakke PS, Bjermer L, et al. Efficacy and safety of 4 weeks' treatment with combined fluticasone furoate/vilanterol in a single inhaler given once daily in COPD: a placebo-controlled randomised trial. BMJ Open. 2012 Jan 19;2(1):e000370.

21 Kelleher DL, Mehta RS, Jean-Francois BM, et al. Safety, tolerability, pharmacodynamics and pharmacokinetics of umeclidinium and vilanterol alone and in combination: a randomized crossover trial. PLoS One. 2012;7(12):e5071

22 Feldman G, Walker RR, Brooks J, et al. 28-Day safety and tolerability of umeclidinium in combination with vilanterol in COPD: a randomized placebo-controlled trial. Pulm Pharmacol Ther. 2012 Dec;25(6):465-71

23. Hu C, Jia J, Dong K, et al. Pharmacokinetics and tolerability of inhaled umeclidinium and vilanterol alone and in combination in healthy Chinese subjects: a randomized, open-label, crossover trial. PLoS One. 2015;10(3):e0121264.

*24. Hanania NA, Feldman G, Zachgo W,et al. The efficacy and safety of the novel long-acting beta2 agonist vilanterol in patients with COPD: a randomized placebo-controlled trial. Chest. 2012 Jul;142(1):119-27.

* An important study on the development of the understanding of Vilanterol use in COPD

25. Kempsford R, Norris V, Siederer S. Vilanterol trifenatate, a novel inhaled long-acting beta2 adrenoceptor agonist, is well tolerated in healthy subjects and demonstrates prolonged bronchodilation in subjects with asthma and COPD. Pulm Pharmacol Ther. 2013 Apr;26(2):256-64.

*26. Svedsater H, Dale P, Garrill K, et al. Qualitative assessment of attributes and ease of use of the ELLIPTA ${ }^{\mathrm{TM}}$ dry powder inhaler for delivery of maintenance therapy for asthma and COPD. BMC Pulm Med. 2013 Dec 7;13:72

* An important study on the development of ELLIPTA device 
27. European Medicines Agency. Anoro (umeclidinium/vilanterol): summary of product characteristics. 2014. http://www.ema.europa. eu/docs/en_GB/document_library/EPAR__Product_Information/ human/002751/WC500168424.pdf. accessed 20 February 2016

28. GlaxoSmithKline. Umeclidinium/vilanterol (Anoro): US prescribing information. 2014. https://www.gsksource.com/gskprm/ htdocs/documents/ANORO-ELLIPTA-PI-MG.PDF. accessed 20 February 2016

29. http://www.ema.europa.eu [homepage on the Internet]. Accessed 20 February 2016

30. [GlaxoSmithKline. Breo Ellipta (fluticasone furoate and vilanterol inhalation powder) prescribing information. 2014. http://us.gsk.com/products/assets/us breo ellipta.pdf\#] Accessed 20 February 2016

31. Crim C, Dransfield MT, Bourbeau J, et al. Pneumonia risk with inhaled fluticasone furoate and vilanterol compared with vilanterol alone in patients with COPD. Ann Am Thorac Soc. 2015 Jan;12(1):27-34.

32. Salmon M, Luttmann MA, Foley JJ, et al. Pharmacological characterization of GSK573719 (umeclidinium): a novel, long-acting, inhaled antagonist of the muscarinic cholinergic receptors for treatment of pulmonary diseases. J Pharmacol Exp Ther. 2013;345(2):260-270.

33. Tal-Singer R, Cahn A, Mehta R, et al. Initial assessment of single and repeat doses of inhaled umeclidinium in patients with chronic obstructive pulmonary disease: two randomised studies. Eur J Pharmacol. 2013;701(1-3):40-48.

34. Decramer $M$, Maltais F, Feldman $G$, et al. Bronchodilation of umeclidinium, a new long-acting muscarinic antagonist, in COPD patients. Respir Physiol Neurobiol. 2013;185(2):393-399.

35. Trivedi R, Richard N, Mehta R, et al. Umeclidinium in patients with COPD: a randomised, placebo-controlled study. Eur Respir J. 2014;43(1):72-81. 
36 Cazzola M, Molimard M.The scientific rationale for combining long-acting beta2-agonists and muscarinic antagonists in COPD. Pulm Pharmacol Ther. 2010

* 37. Celli B, Crater G, Kilbride S, et al. Once-daily umeclidinium/vilanterol 125/25 mcg in COPD: a randomized, controlled study. Chest. 2014 May;145(5):981-91.

* An important study on the development of the understanding of Umeclidinium/Vilanterol use in COPD

** 38. Decramer M, Anzueto A, Kerwin E, et al. Efficacy and safety of umeclidinium plus vilanterol versus tiotropium, vilanterol, or umeclidinium monotherapies over 24 weeks in patients with chronic obstructive pulmonary disease: results from two multicentre, blinded, randomised controlled trials. Lancet Respir Med. 2014 Jun;2(6):472-86.

** A very important study on the development of the understanding of Umeclidinium/Vilanterol use in COPD comared to tandard treatment

39. Donohue JF, Maleki-Yazdi MR, Kilbride S, et al. Efficacy and safety of once-daily umeclidinium/vilanterol 62.5/25 mcg in COPD. Respir Med. 2013 Oct;107(10):1538-46.

40. Donohue JF, Niewoehner D, Brooks J, et al. Safety and tolerability of once-daily umeclidinium/vilanterol $125 / 25 \mathrm{mcg}$ and umeclidinium $125 \mathrm{mcg}$ in patients with chronic obstructive pulmonary disease: results from a 52-week, randomized, double-blind, placebocontrolled study. Respir Res. 2014 Jul 11;15:78.

41. Maltais F, Singh S, Donald AC, et al. Effects of a combination of umeclidinium/vilanterol on exercise endurance in patients with chronic obstructive pulmonary disease: two randomized, double-blind clinical trials. Ther Adv Respir Dis. 2014 Dec;8(6):169-81.

42. Maleki-Yazdi MR, Kaelin T, Richard N, et al. Efficacy and safety of umeclidinium/vilanterol $62.5 / 25 \mathrm{mcg}$ and tiotropium $18 \mathrm{mcg}$ in chronic obstructive pulmonary disease: results of a $24-$ week, randomized, controlled trial. Respir Med. 2014 Dec;108(12):1752-60. 
43. Singh $\mathrm{D}$, Worsley $\mathrm{S}$, Zhu $\mathrm{CQ}$, et al. Umeclidinium/vilanterol versus fluticasone propionate/salmeterol in COPD: a randomised trial. BMC Pulm Med. 2015 Aug 19;15:91.

44. Donohue JF, Worsley S, Zhu CQ, et al. Improvements in lung function with umeclidinium/vilanterol versus fluticasone propionate/salmeterol in patients with moderate-tosevere COPD and infrequent exacerbations. Respir Med. 2015 Jul;109(7):870-81.

45. Donohue JF, Singh D, Munzu C, et al. Magnitude of umeclidinium/vilanterol lung function effect depends on monotherapy responses: Results from two randomised controlled trials. Respir Med. 2016 Jan 7. [Epub ahead of print]

46. Punekar YS, Roberts G, Ismaila A, et al. Cost-effectiveness of umeclidinium/vilanterol combination therapy compared to tiotropium monotherapy among symptomatic patients with chronic obstructive pulmonary disease in the UK. Cost Eff Resour Alloc. 2015 Dec 12;13:22.

*47. Miravitlles M, Gáldiz JB, Huerta A, et al Cost-effectiveness of combination therapy umeclidinium/vilanterol versus tiotropium in symptomatic COPD Spanish patients. Int J Chron Obstruct Pulmon Dis. 2016 Jan 18;11:123-32.

* An importan contribution on cost-effectiveness aspects

48. Ramamoorthy S, Cidlowski JA. Exploring the molecular mechanisms of glucocorticoid receptor action from sensitivity to resistance. Endocr Dev. 2013;24:41-56

49. Caramori G, Casolari P, Adcock I. Role of transcription factors in the pathogenesis of asthma and COPD. Cell Commun Adhes. 2013;20:21-40.

50. Valotis A, Högger P. Human receptor kinetics and lung tissue retention of the enhanced-affinity glucocorticoid fluticasone furoate. Respir Res. 2007;8:54

51. Salter M, Biggadike K, Matthews JL, et al. Pharmacological properties of the enhanced-affinity glucocorticoid fluticasone furoate in vitro and in an in vivo model of respiratory inflammatory disease. Am J Physiol Lung Cell Mol Physiol. 2007;293:L660-L667 
52. Rossios $\mathrm{C}$, To $\mathrm{Y}$, To $\mathrm{M}$, et al. Long-acting fluticasone furoate has a superior pharmacological profile to fluticasone propionate in human respiratory cells. Eur J Pharmacol. 2011;670:244-251.

53. Haque R, KHakim A, Moodley T, et al. Inhaled long-acting b2 agonists enhance glucocorticoid receptor nuclear translocation and efficacy in sputum macrophages in COPD. J Allergy Clin Immunol. 2013;132:1166-73.

*54. Boscia JA, Pudi KK, Zvarich MT, et al. Effect of once-daily fluticasone furoate/vilanterol on 24hour pulmonary function in patients with chronic obstructive pulmonary disease: a randomized, three-way, incomplete block, crossover study. Clin Ther. 2012 Aug;34(8):1655-66

* An important study on the development of the understanding of Fluticasone/Vilanterol use in COPD

55. Kerwin EM, Scott-Wilson C, Sanford L, et al. A randomised trial of fluticasone furoate/vilanterol (50/25 $\mu \mathrm{g} ; 100 / 25 \mu \mathrm{g})$ on lung function in COPD. Respir Med. $2013 \mathrm{Apr} ; 107(4): 560-9$.

56. Martinez FJ, Boscia J, Feldman G, et al. Fluticasone furoate/vilanterol (100/25; 200/25 $\mu \mathrm{g}$ ) improves lung function in COPD: a randomised trial. Respir Med. 2013 Apr;107(4):550-9.

57. A Clinical Outcomes Study to compare the effect of Fluticasone Furoate/Vilanterol Inhalation Powder $100 / 25 \mathrm{mcg}$ with placebo on Survival in Subjects with moderate Chronic Obstructive Pulmonary Disease (COPD) and a history of or at increased risk for cardiovascular disease. Accessible at https://www.clinicaltrialsregister.eu/ctr-search/trial/2010-021638-72/results. Accessed 1 April 2016

58. Dransfield MT, Bourbeau J, Jones PW, et al. Once-daily inhaled fluticasone furoate and vilanterol versus vilanterol only for prevention of exacerbations of COPD: two replicate doubleblind, parallel-group, randomised controlled trials. Lancet Respir Med. 2013 May;1(3):210-23. 
59. Dransfield MT, Feldman G, Korenblat P, et al. Efficacy and safety of once-daily fluticasone furoate/vilanterol $(100 / 25 \mathrm{mcg}$ ) versus twice-daily fluticasone propionate/salmeterol (250/50 mcg) in COPD patients. Respir Med. 2014 Aug;108(8):1171-9.

** 60. Agustí A, de Teresa L, De Backer W, et al. A comparison of the efficacy and safety of oncedaily fluticasone furoate/vilanterol with twice-daily fluticasone propionate/salmeterol in moderate to very severe COPD. Eur Respir J. 2014 Mar;43(3):763-72.

** A very important study on the development of the understanding of Fluticasone/Vilanterol use in COPD

61. Covelli H, Pek B, Schenkenberger I, et al. Efficacy and safety of fluticasone furoate/vilanterol or tiotropium in subjects with COPD at cardiovascular risk. Int J Chron Obstruct Pulmon Dis. 2015 Dec $18 ; 11: 1-12$

62. Siler TM, Kerwin E, Sousa AR, et al. Efficacy and safety of umeclidinium added to fluticasone furoate/vilanterol in chronic obstructive pulmonary disease: Results of two randomized studies. Respir Med. 2015 Sep;109(9):1155-63.

63. Huisman EL, Cockle SM, Ismaila AS, et al. Comparative efficacy of combination bronchodilator therapies in COPD: a network meta-analysis. Int J Chron Obstruct Pulmon Dis. 2015 Sep 9;10:186381.

64. * Oba Y, Sarva ST, Dias S. Efficacy and safety of long-acting $\beta$-agonist/long-acting muscarinic antagonist combinations in COPD: a network meta-analysis. Thorax. 2016 Jan;71(1):15-25.

* A important network meta-analisys of LABA/LAMA combinations in COPD 65. Horita N, Miyazawa N, Tomaru K, et al. Long-acting muscarinic antagonist + long-acting beta agonist versus long-acting beta agonist + inhaled corticosteroid for COPD: A systematic review and meta-analysis. Respirology. 2015 Nov;20(8):1153-9. 
66. Schlueter M, Gonzalez-Rojas N, Baldwin M, et al. Comparative efficacy of fixed-dose combinations of long-acting muscarinic antagonists and long-acting $\beta 2$-agonists: a systematic review and network meta-analysis. Ther Adv Respir Dis. 2016 Jan 8. [Epub ahead of print]

*67. Malerba M, Morjaria JB, Radaeli A. Differential pharmacology and clinical utility of emerging combination treatments in the management of COPD - role of umeclidinium/vilanterol. Int $\mathrm{J}$ Chron Obstruct Pulmon Dis. 2014;9:687-695.

*An important review addressing Umeclidinum/vilanterol use in COPD treatment

Figure 1 and 2: Trough $\mathrm{FEV}_{1}$ values ( $\mathrm{ml}$ ) in the different treatments branches testing the efficacy of UMEC/VIL in COPD: results of the main clinical trials published.

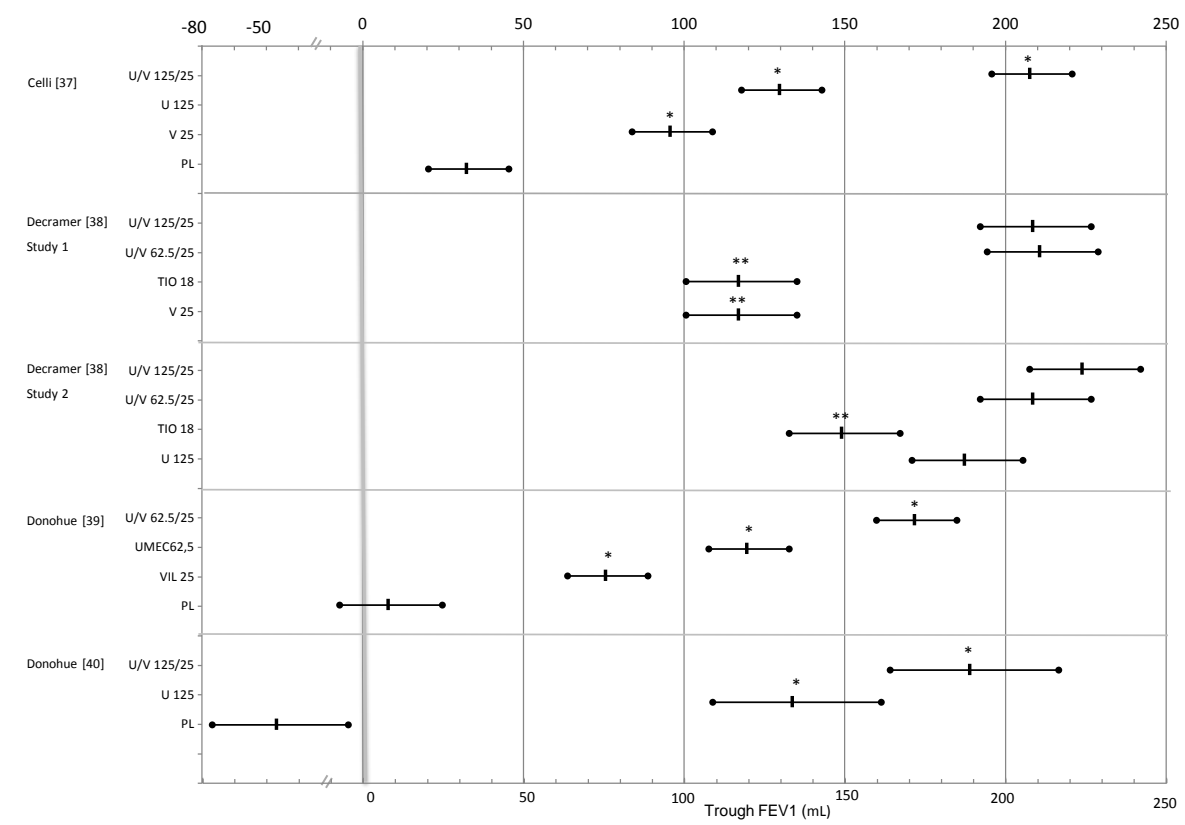

Figure 1: Trough FEV 1 values (ml) in the different treatments branches testing the efficacy of UMEC/VIL in COPD: results of the main clinical trials published. (Continue in Figure 2) Figure
(Values expressed as LS mean changesfrom baseline and standard errors. ${ }^{*} p<0.01$ vs placebo, ${ }^{* *} p<0.01$ vs both combined doses) 
Figure 2 : Trough FEV1 values $(\mathrm{ml})$ in the different treatments branches testing the efficacy of UMEC/VIL in COPD : results of the main clinical trials published (continuation) (Values expressed as LS mean changes from baseline and standard errors. ${ }^{*} p<0.01$ vs placebo, * $p<0.01$ vs other treatment, $H$ - not significant due to statistical Hierarchy, NR: not reported in published paper)
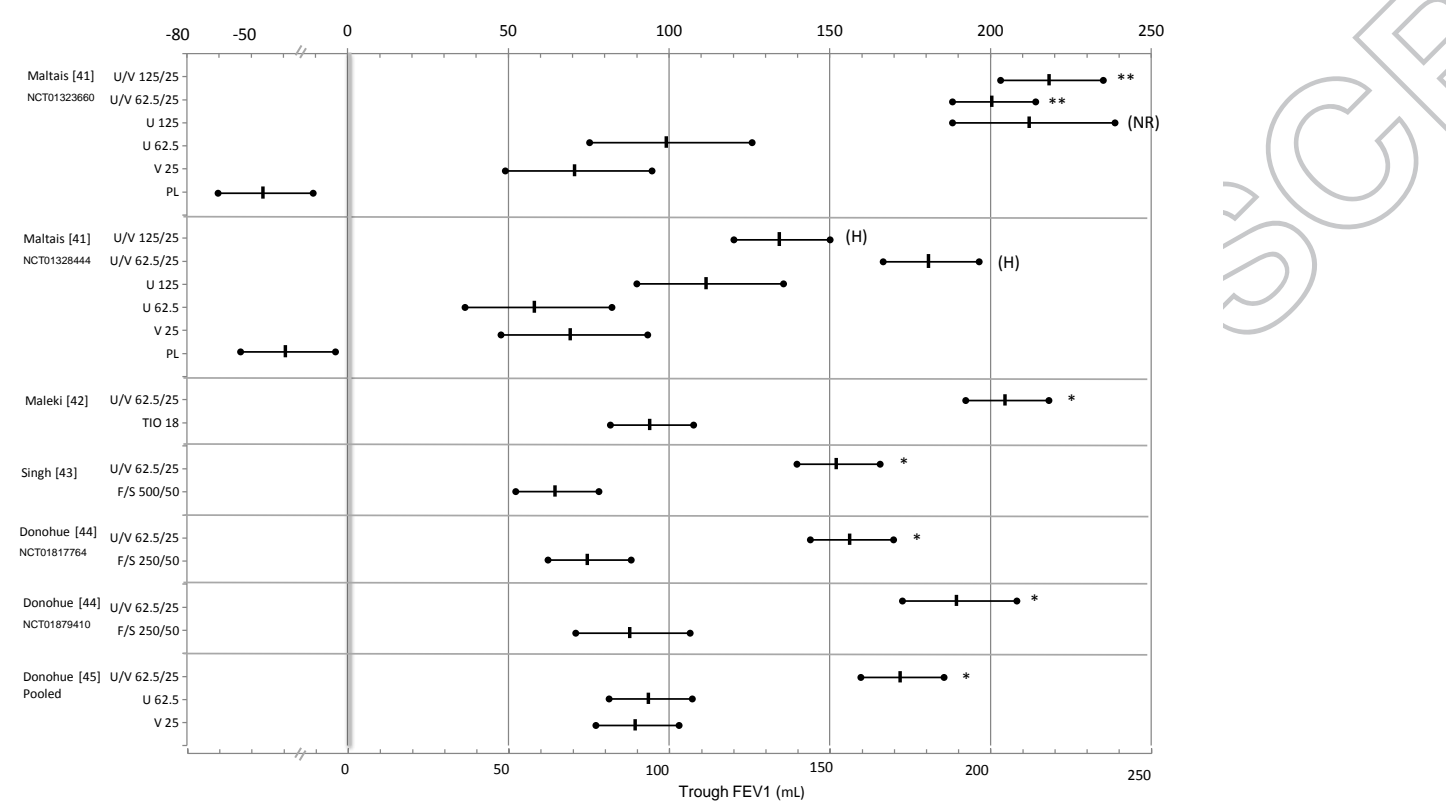

Figure 2: Trough FEV1 values (ml) in the different treatments branches testing the efficacy of UMEC/VIL in COPD: results of the main clinical trials published (continuation)

(Values expressed as LS mean changes from baseline and standard errors. * ${ }^{*}<0.01$ vs placebo, " $p<0.01$ vs other treatment, $H$ - not significant due to statistical Hierarchy, NR: not reported in 
Figure 3: Trough $\mathrm{FEV}_{1}$ values $(\mathrm{ml})$ in the different treatments branches testing the efficacy of FF/VIL in COPD: results of the main clinical trials published.
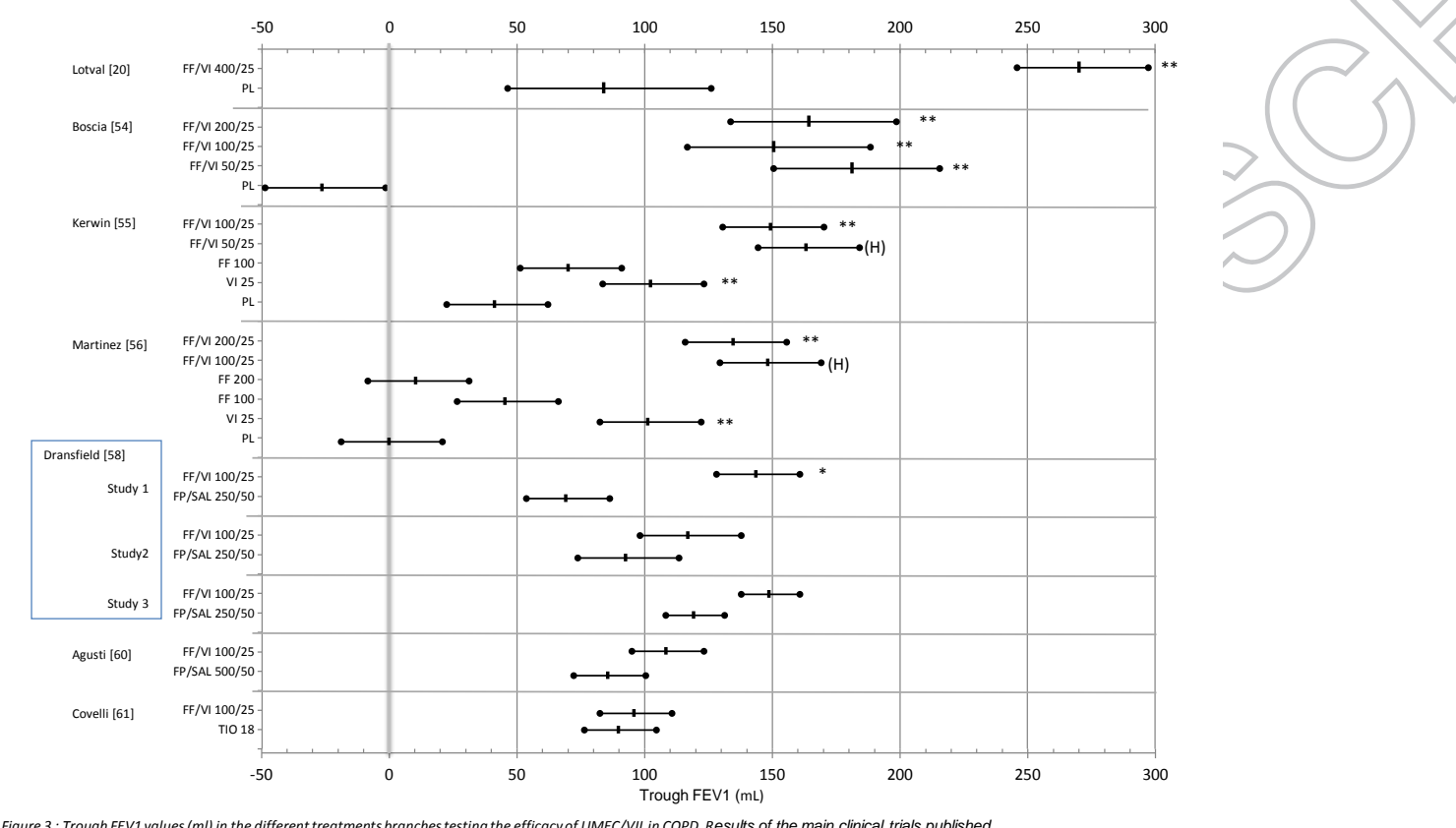


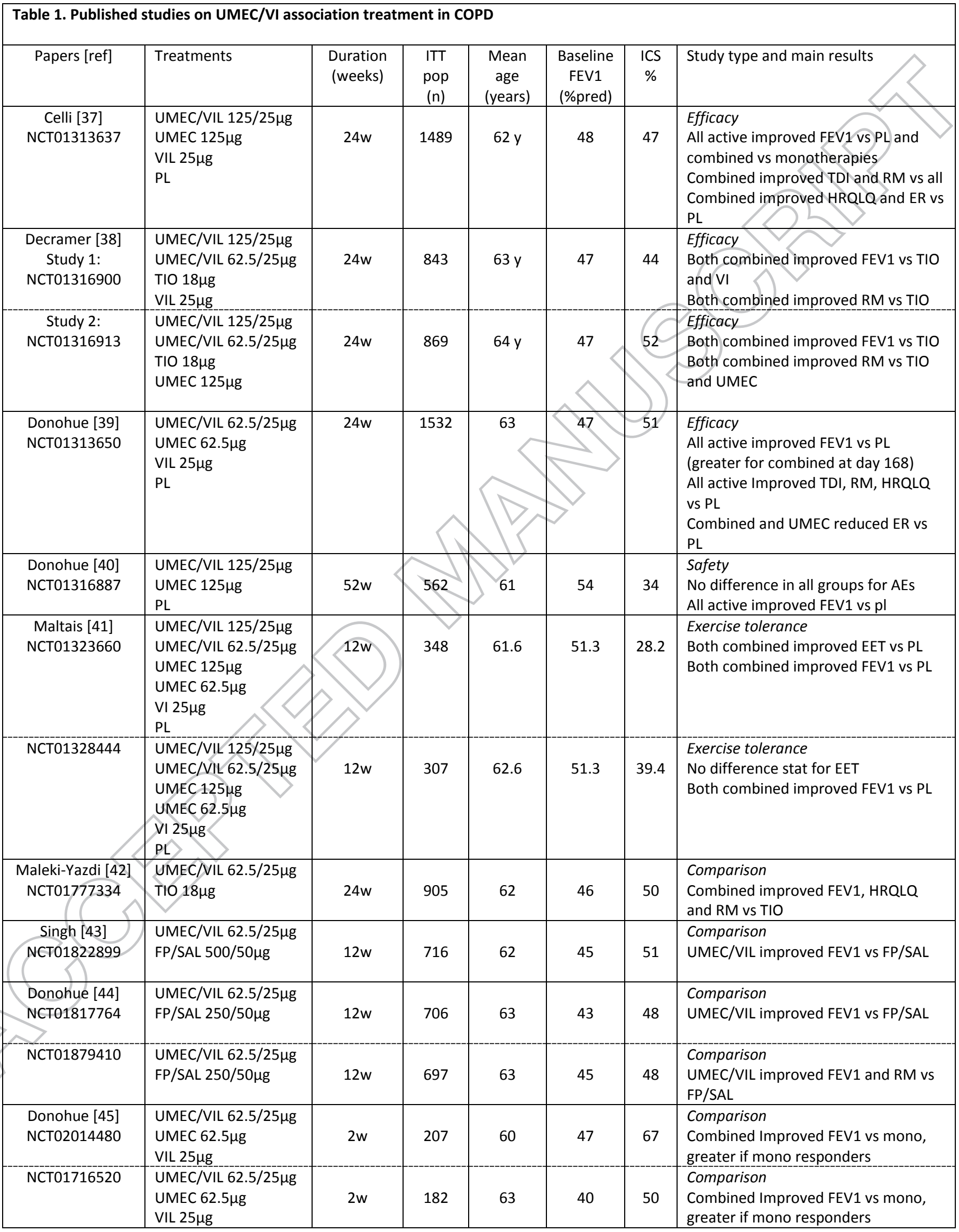


Abbreviations: UMEC - Umeclidinium; VI - Vilanterol; Dur - duration; ITT pop - Intention to treat population; FEV ${ }_{1}$ - Forced expiratory flow in 1 second; pred - predicted; ICS - inhaled corticosteroids; PL - Placebo; W - weeks; Y - years; TDI - transitional dyspnoea index; RM rescue medication; HRQLQ - health related quality of life questionnaire; ER - exacerbation rate; TIO - tiotropium; EET - exercise endurance time; FP - fluticasone propionate; SAL - salmeterol. 


\begin{tabular}{|c|c|c|c|c|c|c|}
\hline Papers [ref] & Treatments & $\begin{array}{l}\text { Duration } \\
\text { (weeks) }\end{array}$ & $\begin{array}{l}\text { ITT } \\
\text { pop } \\
(\mathrm{n})\end{array}$ & $\begin{array}{c}\text { Mean } \\
\text { age } \\
\text { (years) }\end{array}$ & $\begin{array}{l}\text { Baseline } \\
\text { FEV1 (\% } \\
\text { pred) }\end{array}$ & Study type and main results \\
\hline $\begin{array}{c}\text { Lotval [20] } \\
\text { NCT00731822 }\end{array}$ & $\begin{array}{l}\mathrm{FF} / \mathrm{VI} 400 / 25 \mu \mathrm{g} \\
\mathrm{PL}\end{array}$ & $4 w$ & 60 & 63 & 59 & $\begin{array}{l}\text { Efficacy and safety } \\
\text { No differences for HR or BP, combined } \\
\text { showed more AEs } \\
\text { Combined improved FEV1 vs PL. }\end{array}$ \\
\hline $\begin{array}{c}\text { Boscia [54] } \\
\text { NCT01072149 }\end{array}$ & 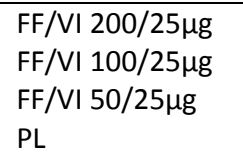 & $7 w$ & 54 & 58 & 50 & $\begin{array}{l}\text { Efficacy } \\
\text { Alla combined improved FEV1 }\end{array}$ \\
\hline $\begin{array}{c}\text { Kerwin [55] } \\
\text { NCT01053988 }\end{array}$ & 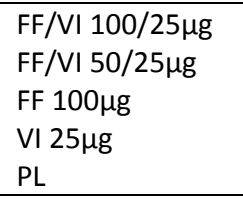 & $24 w$ & 1030 & 62 & 42 & $\begin{array}{l}\text { Efficacy } \\
\text { All combined improved F } \\
\text { RM vs PL } \\
\text { No difference for ER }\end{array}$ \\
\hline $\begin{array}{l}\text { Martinez [56] } \\
\text { NCT01054885 }\end{array}$ & 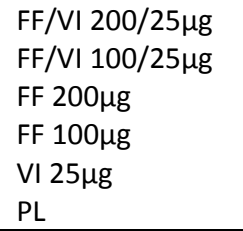 & $24 w$ & 1224 & 61 & 43 & $\begin{array}{l}\text { Efficacy } \\
\text { Al combined and VI improved FEV1, } \\
\text { HRQLQ VSPL }\end{array}$ \\
\hline $\begin{array}{l}\text { Dransfield [58] } \\
\quad \text { Study } 1 \\
\text { NCT01323634 }\end{array}$ & 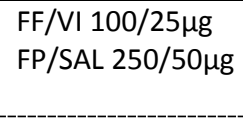 & $12 w$ & 519 & 61 & & $\begin{array}{l}\text { Comparison } \\
\text { FF/VIimproved FEV1 vs FP/SAL }\end{array}$ \\
\hline $\begin{array}{l}\text { Study } 2 \\
\text { NCT01323621 }\end{array}$ & $\begin{array}{l}\mathrm{FF} / \mathrm{VI} 100 / 25 \mu \mathrm{g} \\
\mathrm{FP} / \mathrm{SAL} 250 / 50 \mu \mathrm{g}\end{array}$ & $12 w$ & 511 & & & $\begin{array}{l}\text { Comparison } \\
\text { No differences }\end{array}$ \\
\hline $\begin{array}{c}\text { Study } 3 \\
\text { NCT01706328 }\end{array}$ & 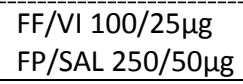 & $12 w$ & 828 & 61 & 48 & $\begin{array}{l}\text { Comparison } \\
\text { No differences }\end{array}$ \\
\hline $\begin{array}{l}\text { Dransfield [59] } \\
\quad \text { Study } 1 \\
\text { NCT01009463 }\end{array}$ & 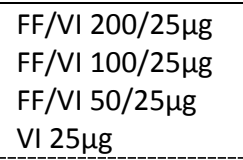 & $52 w$ & 27 & 63 & 45 & $\begin{array}{l}\text { Exacerbation Rate } \\
\text { No difference for exacerbation rate } \\
\text { All combined improved FEV1 vs VI }\end{array}$ \\
\hline $\begin{array}{l}\text { Study } 2 \\
\text { NCT01017952 }\end{array}$ & 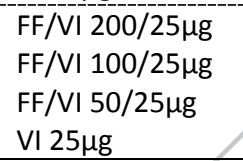 & & 1633 & 63 & 45 & $\begin{array}{l}\text { Exacerbation rate } \\
\text { All Combined showed fewer } \\
\text { exacerbation rate vs VI } \\
\text { All combined improved FEV1 vs VI }\end{array}$ \\
\hline $\begin{array}{c}\text { Agusti [60] } \\
\text { NCT01342913 }\end{array}$ & $\mathrm{FF} /$ & & 528 & 63 & 47 & $\begin{array}{l}\text { Comparison } \\
\text { No difference for FEV1 between } \\
\text { treatments }\end{array}$ \\
\hline $\begin{array}{c}\text { Covelli [61] } \\
\text { NCT01627327 }\end{array}$ & $\mathrm{FF} / \mathrm{V} / 10$ & $12 w$ & 623 & 62 & 48 & $\begin{array}{l}\text { Comparison } \\
\text { No difference for FEV1 between } \\
\text { treatments } \\
\text { Combined improvements in RM, TDI, } \\
\text { HRQLQ vs TIO* } \\
\text { Tio improved IC and FVC vs combined* } \\
\text { (*not statistically significant due to } \\
\text { statistical hierarchy) }\end{array}$ \\
\hline \multicolumn{7}{|c|}{$\begin{array}{l}\text { Abbreviations: FF - Fluticasone furoate; } \mathrm{VI} \text { - Vilanterol; Dur - duration; ITT pop - Intention to treat population; FEV }{ }_{1} \text { - Forced } \\
\text { expiratory flow in } 1 \text { second; pred - predicted; PL - Placebo; W - weeks; Y - years; HR - heart rate; BP - blood pressure; AEs - } \\
\text { adverse events; TDI - transitional dyspnoea index; RM - rescue medications; HRQLQ - health related quality of life questionnaire; } \\
\text { TIO - tiotropium; EET - exercise endurance time; FP - fluticasone propionate; SAL: salmeterol. }\end{array}$} \\
\hline
\end{tabular}

